\title{
Retrosternal goitre at Pietersburg Hospital, Limpopo Province, South Africa: A case report
}

\author{
T Gvilia MD, FCS, PhD; L Jonas MB ChB, FCS (SA), MMed; A B van As, MB ChB, FCS (SA), MMed, MBA, PhD
}

Department of General Surgery, Pietersburg and Mankweng Academic Health Complex, University of Limpopo, Polokwane, South Africa

Corresponding author: T Gvilia (tamazdoc@gmail.com)

\begin{abstract}
Retrosternal goitre presents in $2-19 \%$ of all thyroidectomies. Surgical removal is the treatment of choice. We report a case of an anterior retrosternal goitre, which was removed by a combined cervical/sternotomy approach.

S Afr Med J 2021;111(11b):1140-1141. https://doi.org/10.7196/SAMJ.2021.v111i11b.16102
\end{abstract}

A retrosternal goitre (RG) is an enlarged thyroid gland extending into the mediastinum. Retrosternal goitre is diagnosed when $50 \%$ of the thyroid gland is below the thoracic inlet. ${ }^{[1,2]}$ The presence of RG is documented in $2-19 \%$ of all thyroidectomies. ${ }^{[2]}$

Most RGs are situated in the anterior mediastinal compartment. Posterior mediastinal goitres are uncommon, comprising 10 - 15\% of all mediastinal goitres. ${ }^{[3]}$

The rate of malignancy in reported surgical series is low $(6-21 \%){ }^{[4]}$ Large RG may cause airway and oesophageal compression; therefore, surgery is indicated when the diagnosis is confirmed. ${ }^{[5]}$

\section{Case report}

A 63 -year-old woman with a history of goitre for $>10$ years was referred from one of the regional hospitals in Limpopo Province, South Africa. The patient reported dysphagia and odynophagia. Local examination showed a diffuse swelling/large mass on the anterior aspect of the neck. Her comorbidities were asthma and diabetes mellitus type I. The diagnoses of a massive RG was suspected by a thyroid ultrasound, which showed a multinodular goitre with retrosternal extension. Chest X-ray showed an anterior mediastinal mass with deviation of the trachea. The diagnosis was confirmed with a contrast-enhanced computed tomography (CT) scan of the neck and chest, which showed significantly enlarged thyroid with anterior mediastinal extension bilaterally and the left lobe extending down to the superior border of the heart (Figs 1A and B).

The thyroid function test was as follows: TSH $0.70 \mathrm{MIU} / \mathrm{L}$, T4 $(8.2 \mathrm{pmol} / \mathrm{L})$, and T3 $(4.0 \mathrm{pmol} / \mathrm{L})$. Fine-needle aspiration confirmed the diagnosis of a multinodular goitre with no evidence of malignancy. The patient was prepared for surgery. An awake intubation was done using fibreoptic laryngoscopy by our anaesthetic team. The patient was positioned in a supine position with the neck extended by placing a shoulder roll in between the scapulae. We performed the surgery using a combined cervical incision and midline sternotomy. First, we made collar-shaped incision in anterior aspect of the neck. The thyroid gland was exposed though sharp dissection of the layers of the wall of the neck.

The thyroid gland was mobilised from the right side. After dissection of the right lobe, we continued to the left side. The recurrent laryngeal nerves were identified bilaterally and preserved. The thyroid arteries and veins were divided and ligated. A partial sternotomy was done, and the intrathoracic portion of the gland was removed by blunt finger dissection. The thyroid gland with retrosternal extension was completely removed successfully (Fig. 2).

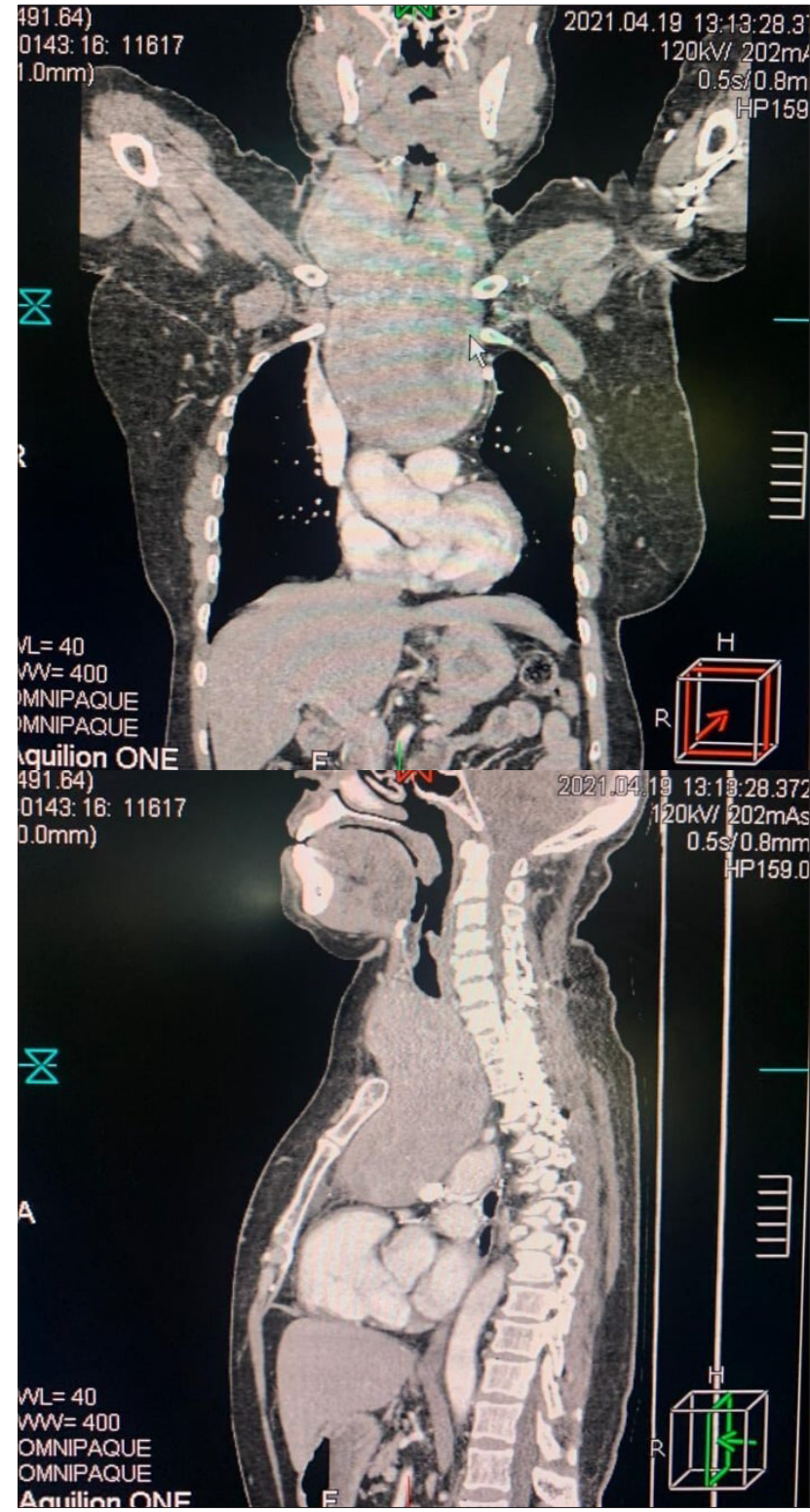

Fig. 1. Antero-posterior and lateral views of contrast-enhanced computed tomography scan of the neck and chest, demonstrating a multinodular goitre with extending retrosternally up to the superior border of the heart. 
Haemostasis was achieved, and the mediastinal pleura was intact. A suction drain was inserted, and the wound closed in layers (Fig. 3).

The patient was doing well postoperatively, with voice changes. She

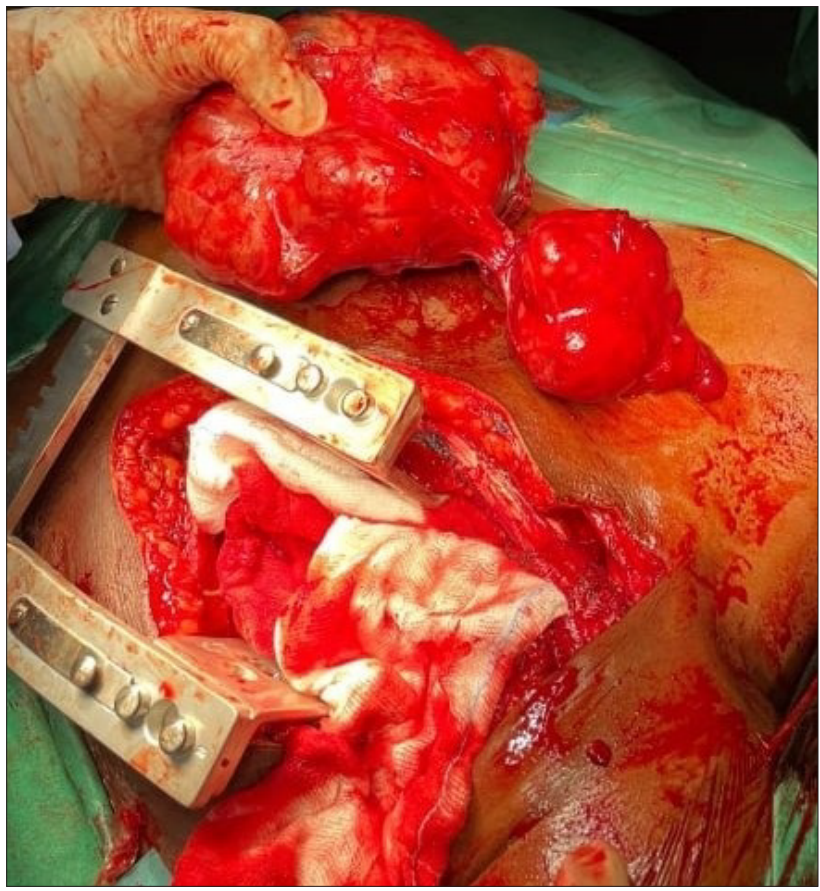

Fig. 2. Partial sternotomy and removal of the retrosternal thyroid mass.

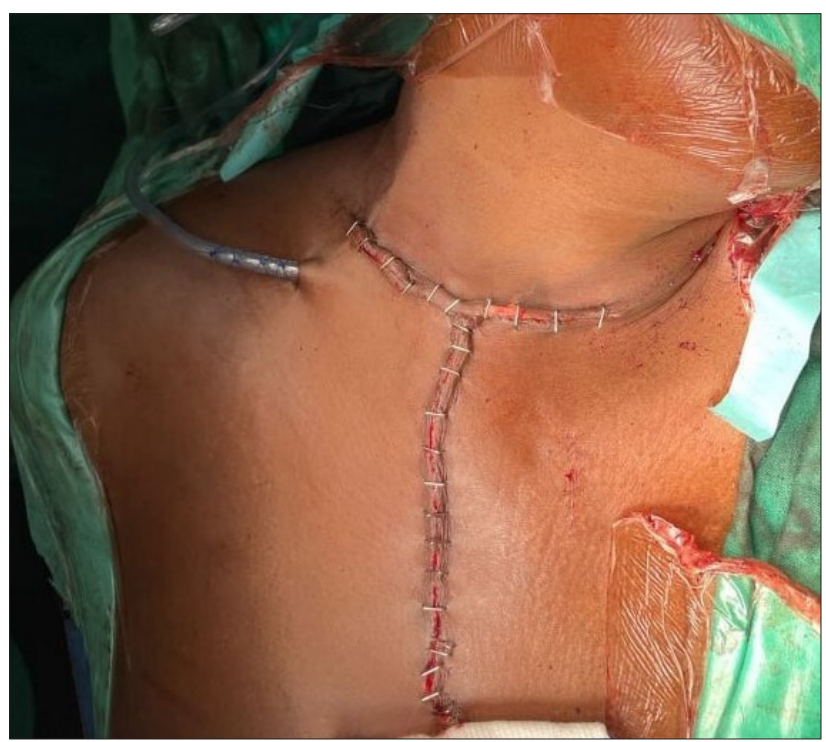

Fig. 3. A suction drain was inserted and the wound was closed with staples. had a mild hypocalcaemia of $1.92 \mathrm{mmol} / \mathrm{L}$, with a normal parathyroid hormone level of $6.2 \mathrm{pmol} / \mathrm{L}$. She was discharged on day 7 after the operation and was put on treatment with eltroxine (100 $\mu$ g daily) and calcium gluconate (500 mg daily). During follow-up at the clinic, histology showed a $585 \mathrm{~g}$ goitre with no evidence of malignancy, only features of multinodular goitre.

\section{Discussion}

Massive long-standing goitres are common in iodine-deficient areas. RGs are more common among women, the symptoms are related to compression of the airway and pressure on mediastinal structures.

One of the most reliable classifications is considering the degree of the intrathoracic extension of the thyroid gland:

- largely intrathoracic (more than $80 \%$ );

- partially intrathoracic (more than $50 \%$, but less than $80 \%$ ); and

- substernal goitre (more than $50 \%$ remaining in the neck). ${ }^{[6]}$

Surgical removal of a RG is a challenging procedure, cervical approach is suitable for $95 \%$ of the cases. The need for sternotomy increases greatly if a significant proportion of the gland is located in the mediastinum or the RG is in a retrotracheal or retro-oesophageal position, or if the intrathoracic component is significantly larger than the cervical one. ${ }^{[4]}$

\section{Conclusion}

RG is a rare condition. A CT scan should always be included in the pre-operative diagnostic work-up when RG is suspected. ${ }^{[2]}$ Surgical removal is the treatment of choice in such cases. Combined cervical collar incision and sternotomy gives good exposure and makes it easy to remove large RGs.

Declaration. None.

Acknowledgements. None.

Author contributions. Equal contributions.

Funding. None.

Conflicts of interest. None.

1. Akheel M, Nagarkar R, Roy S, Wadhawania A. Huge nodular goitre with retrosternal extension - A rare case report. J Otolaryngol ENT Res 2017;7(4):00215. https://doi.org/10.15406/joentr.2017.07.00215

2. Rugiu MG, Piemonte M. Surgical approach to retrosternal goitre: Do we still need sternotomy? Acta Otorhinolologica Ital 2009;29(6):331-338.

3. Kacprazk G, Karas J, Rzechonek A, Blasiak P. Retrosternal goiter located in the mediastinum: Surgical approach and operative difficulties. Interactive Cardio-vascular Thoracic Surg 2012;15:935-937. https// dx.doi.org/10.1093/icvts/ivs339

4. Simo R, Nixon I, Ofo E. Surgery for intrathoracic (retrosternal) goitres. Atlas Operative Otorhinolaryngology Neck Surg 2018;1:23. https://doi.org/10.15641//0-7992-2534-1

5. Gao B, Jaing Y, Zhang X, et al. Surgical treatment of large substernal thyroid goitre: Analysis of 12 patients. Int J Clin Exp Med 2013;6(7):488-496.

6. Matar Z, Alkwami M, Mohamed A, Abuhkater M. Neglected retrosternal goitre. Internet J Surg 2007:16(1). https://ispub.com/IJS/16/1/7704 (Accessed date).

Accepted 4 September 2021. 